\title{
A representação da realeza no Brasil: uma análise dos retratos de D. João VI e D. Pedro I, de Jean-Baptiste Debret
}

\begin{abstract}
Elaine Dias $^{1}$
RESUMO: Jean-Baptiste Debret, pintor de história e integrante da Missão Artística Francesa de 1816, em seu álbum iconográfico Viagem pitoresca e histórica ao Brasil, realizou ilustrações referentes aos usos e costumes brasileiros. Uma parte de sua obra foi dedicada à vida de corte no Rio de Janeiro. Pretendemos, neste artigo, analisar a concepção do Retrato de D. João VI e do Retrato de D. Pedro I, imagens oficiais da realeza no Brasil, produzidas pelo artista francês. Há, em Debret, uma clara contraposição entre os retratos do pai D. João e do filho Pedro, oferecendo-nos chaves interpretativas para os momentos políticos em questão. Pretendemos analisar e contrapor as imagens, no sentido de sua descrição física, da presença diferencial dos atributos e de sua representação política, evidenciando as mudanças iconográficas entre os retratos e destacando a importância dos modelos europeu e americano nas composições.

PALAVRAS-ChAVE: Retrato. D. João VI. D. Pedro I. Jean-Baptiste Debret. Henrique José da Silva. Hyacinthe Rigaud.

ABSTRACT: Jean-Baptiste Debret, history painter and member of the French Artistic Mission of 1816, in his iconographic album Picturesque and Historical Travel to Brazil, has made illustrations from the observation of Brazilian uses. Part of his work was dedicated to the life of the Court in Brazil. The author seeks to in this article to analyze the conception of both the Portrait of D. João VI and the Portrait of D. Pedro I, official images of the Royalty in Brazil produced by the French artist. There is, in Debret, a clear counterpoint between the portraits of the father D. João and his son Pedro, offering interpretative keys for the political moments in question. The author seeks to analyze and contrast the images, in the sense of their physical description - the differential presence of attributes and their political representation -, bringing to the surface the iconographic changes between the portraits, highlighting the importance of the European and American models in the compositions.

KEYWORDS: Portrait. D. João VI. D. Pedro I. Jean-Baptiste Debret. Henrique José da Silva. Hyancinthe Rigaud.
\end{abstract}

1. Bolsista Fapesp de pósdoutoramento em Fundamentos da Arquitetura e do Urbanismo (FAU-USP,). E-mail: nanidias@hotmail. com 
2.Ver DIAS, 2001.

3. MIGLIACCIO, 2000.

Jean-Baptiste Debret é o primeiro pintor de história a realizar um conjunto de pinturas voltadas à representação da corte portuguesa no Rio de Janeiro. A obra Viagem pitoresca e histórica ao Brasil, produzida por Debret e publicada em três volumes entre 1834 e 1839, em Paris, apresenta uma série de ilustrações correspondentes aos principais eventos ocorridos no reinado de D. João VI e império de D. Pedro I, além da construção de uma iconografia de caráter nacionalista, inteiramente nova, relativa ao Primeiro Império.

A análise minuciosa de algumas dessas imagens permite-nos compreender o discurso pictórico elaborado por Debret a partir de contextos políticos específicos. Suas aquarelas e pinturas, a maioria realizada entre 1816 e 1831 - anos, respectivamente, de sua chegada ao Brasil e de sua partida -, que mais tarde serão gravadas e inseridas em seu álbum, muitas vezes funcionam como uma composição narrativa que transmite uma mensagem histórica ${ }^{2}$. Em suas composições, Debret constrói a cena de maneira a transmitir a verossimilhança dos fatos, partindo sempre da escolha de determinados efeitos que funcionam como instrumentos de persuasão contidos na mensagem. Estes meios são inteiramente derivados de sua formação neoclássica, em Paris, com o pintor francês Jacques-Louis David.

É essencial ressaltarmos a relação direta que se estabelece entre sua formação como pintor de história em Paris - cuja relação com o mestre David é notória - e a composição de suas pinturas, cenografias e aquarelas, num contexto de vivência e aprendizado da sociedade brasileira ainda em fase de constituição. Sua formação francesa está intimamente ligada à produção brasileira, uma vez que a concepção artística derivada do neoclassicismo francês foi aqui retomada na construção iconográfica de temas relativos à sociedade e à política brasileiras ${ }^{3}$.

Debret trabalhara com David em Paris e também em Roma, quando da produção do célebre quadro $\bigcirc$ juramento dos Horácios, exposto no Salão parisiense de 1785. Criando a escola neoclássica - onde se destacavam pintores como François Gérard, Antoine-Jean Gros, Pierre-Narcisse Guérin e o próprio Debret (DELECLUZE, 1983) -, David levava adiante o exemplo grego a ser retomado. De volta à Paris, Debret se une a essa escola davidiana na realização de um corpus de pintura neoclássica destinada à exaltação política do período revolucionário, cujas telas tinham como modelo, num primeiro momento, a Antiguidade Clássica e, anos mais tarde, a exaltação ao gênio contemporâneo de Napoleão. Destacamos, entre suas principais obras, as telas Régulo voltando a Cartago, que obteve o prêmio de pintura de 1791, e Aristodemo liberto por uma moça, exposta no Salão de 1798. Nesses dois trabalhos, Debret ainda se concentrava nos modelos ideais da Antiguidade Clássica, exemplos de patriotismo e militarismo, que tão bem se associavam àquele momento político francês (BOIME, 1987; FRIEDLANDER, 2001). Anos mais tarde, Debret atualizou a mensagem histórica na exaltação a Napoleão. Suas telas A primeira distribuição da Legião de Honra pelo imperador na igreja dos Inválidos e Napoleão 
homenageia a coragem infeliz, obras expostas respectivamente nos Salões de 1806 e 1812 , mostravam a atuação de Napoleão nas campanhas européias. Desta forma, procurava não mais através dos temas clássicos, mas por meio do viés contemporâneo, traduzir o momento histórico vivido. Os modelos gregos e romanos de outrora davam lugar aos fatos atuais, conservando seu caráter patriótico e glorioso.

Em 1815, com a queda de Napoleão e o início de um processo de emigração que se instalava na França em decorrência da Restauração dos Bourbons, além de alguns problemas pessoais resultantes da morte de um filho, Debret aproximou-se de Joachim Le Breton, na esperança de integrar o projeto de uma escola de artes e ofícios no Rio de Janeiro. Nesse mesmo ano, Le Breton integrou-o como professor de pintura de história, ao lado do pintor de paisagem Nicolas-Antoine Taunay, então membro do Institut de France, e do arquiteto Grandjean de Montigny, entre outros ${ }^{4}$. Debret abandonava a Paris outrora revolucionária, cujo futuro se mostrava incerto aos artistas bonapartistas, e partia para a América portuguesa, para onde se deslocara a corte dos Bragança.

A chegada da denominada Missão Artística Francesa ao Rio de Janeiro, em março de 1816 , com vistas à fundação de uma Escola de Ciências, Artes e Ofícios, levou os artistas à realização de diversos trabalhos. Estavam dispostos a celebrar a imagem da corte dos Bragança, que agora reinava no Brasil sob novas condições políticas. A rainha Dona Maria I acabara de falecer e o príncipe D. João estava prestes a ser aclamado novo rei. Enquanto Le Breton elaborava o plano de ensino destinado à futura escola de artes e ofícios, esperando sua fundação, Debret e os demais componentes da Missão envolviamse principalmente nas decorações festivas para as grandes solenidades públicas, entre as quais o casamento da arquiduquesa Leopoldina com o príncipe D. Pedro, em 1817, e a aclamação de D. João VI ao reinado, em 1818. Debret e o arquiteto Grandjean de Montigny, já habituados às festas de consagração política anteriormente realizadas em Paris sob a direção dos arquitetos Percier e Fontaine, colocavam em prática a experiência francesa nas festas luso-brasileiras. Ao lado de artistas e engenheiros militares portugueses, contribuíram para o engrandecimento político da corte perante seus súditos, com a construção de arcos de triunfo efêmeros, pinturas e suntuosas iluminações espalhadas pela capital carioca do novo Reino.

Como pintor de história e membro do grupo que fundaria a escola projetada por Le Breton, Debret tentava exercer aqui o mesmo papel que exercera na França. Inicia a produção de cenas que revelassem a nova condição política brasileira, seja por meio da realização de aquarelas e pinturas, seja na produção das decorações para a exaltação daquele momento político. As dificuldades enfrentadas nos primeiros anos no Brasil - entre as quais a falta de materiais e ateliês apropriados, a ausência de apoio institucional, uma vez que a Escola não fora fundada, e, por último, uma série de divergências que se instalava dentro e fora do grupo de franceses ${ }^{5}$-, não permitia, no entanto, que os trabalhos seguissem os mesmos moldes de Paris. A grande pintura de história passava a ser representada nas aquarelas e decorações das festas públicas. Várias dessas aquarelas
4. Sobre a chegada dos artistas franceses ao Brasil e as relações entre Le Breton e o governo português, ver DIAS, 2005.

5. O artigo Uma carta de Jean-Baptiste Debret ao "Camarade De La Fontaine" na Bibliothèque de l'INHA (França): novos relatos para a história da Missão Artística Francesa no Brasil, publicado na Revista de História e Arqueologia da Unicamp, n. 5, 2006, discute as divergências dentro do próprio grupo de franceses, principalmente entre Taunay e Le Breton; e, ainda, algumas tensões entre Taunay e Debret na corte de D. João VI. 
6. LEVY, Revista do SPHAN, n.9, p. 251, 1945

7. Estes retratos podem ser visualizados ainda hoje na Santa Casa de Misericórdia do Rio de Janeiro, expostos em seus cor redores. converteram-se posteriormente num pequeno número de telas a óleo, que procuravam traduzir os grandes momentos vividos na política brasileira, como o Retrato de D. João VI (1817) e o Desembarque da arquiduquesa Leopoldina, em 1816, óleos que hoje pertencem ao Museu Nacional de Belas Artes, no Rio de Janeiro.

Propomos, neste artigo, uma análise da retratística oficial de D. João $\mathrm{VI}$ e D. Pedro I realizada por Debret, de maneira a identificar a estreita relação estabelecida entre sua formação francesa e a criação de imagens para a corte no Brasil. Esta relação, operada por Debret, traz importantes informações históricas sobre o momento político de exaltação da Monarquia, constituindo elementos visuais fundamentais ao entendimento dos eventos políiticos da época e da própria história da arte brasileira no século XIX.

Breves considerações sobre a retratística no Brasil

A retratística no Brasil esteve, durante todo o período colonial, quase inteiramente vinculada às instituições religiosas. Nos conventos e santas casas das principais capitanias brasileiras, entre as quais Bahia, Rio de Janeiro e São Paulo ${ }^{\circ}$, era encontrada uma grande quantidade de retratos. Não era prática corrente da sociedade colonial a encomenda de retratos para decorar as casas, nem o gênero constituía um símbolo de status social. No caso das instituições, os retratos coloniais eram estreitamente ligados à tradição religiosa das ordens, irmandades e confrarias portuguesas e representavam, em sua maioria, os benfeitores dessas instituições, homenageados, em vida e após a sua morte, com a produção de seus retratos.

Em sua obra Viagem pitoresca e histórica ao Brasil, Debret menciona essa tradição e afirma sua importância na sociedade colonial. Descreve a Santa Casa de Misericórdia no Rio de Janeiro e a coleção de retratos a óleo de seus fundadores e doadores ${ }^{7}$. Segundo ele, o retrato do doador só era colocado no hospital depois de sua morte, pintado de corpo inteiro, geralmente com a representação da Santa Casa ao fundo. Eram retratos de composição simples. Debret também menciona informações sobre aqueles que estão representados e sobre as melhorias das técnicas de composição, ocorridas com o decorrer dos anos. Nos retratos mais antigos, o doador mantinha-se com o chapéu à mão, com sua bengala ou simplesmente de pé, sendo os mais recentes representados com trajes mais sofisticados, mostrando os papéis referentes às doações feitas à Santa Casa. Os retratos, em sua maioria, seguiam um modelo de composição identificado pela posição estática do retratado na cena construída no primeiro plano, um cenário com a presença de algum móvel e, ao fundo, a paisagem da instituição a que o homenageado pertencesse. Os trajes e o papel institucional desempenhado pelos homenageados eram os atributos essenciais do retrato, cuja função era estritamente pública e honorífica. Debret cita os pintores José Leandro e Simplício Rodrigues de Sá ao tratar desses últimos retratos, sem analisar, contudo, suas produções. 
No início do século XIX, a produção de retratos no Rio de Janeiro deslocou-se moderadamente para o âmbito social, principalmente com a atuação de alguns poucos alunos de Manuel Dias de Oliveira, o Romano, que, a partir do aprendizado na Accademia di San Luca, em Roma, e a exemplo da Aula Régia de Desenho de Lisboa, implantava no Brasil, em 1800, uma Aula Pública de Desenho e Figura. Mas foi somente após a chegada da Corte Portuguesa em 1808 e, principalmente, da Missão Artística em 1816, que a produção de retratos escapou definitivamente da primazia religiosa. Acentuou-se a produção de retratos de figuras ilustres da política da corte, constatando-se, assim, o desenvolvimento da retratística voltada ao âmbito oficial. Neste gênero, no final do século XVIII e nos primeiros anos do século XIX, destacaram-se artistas como José Leandro de Carvalho, Leandro Joaquim, Francisco Pedro do Amaral e Simplício Rodrigues de Sá, cujas produções já se destacavam antes da chegada dos pintores franceses. Entre as obras realizadas, são significativos o retrato do quarto vice-rei do Brasil, entre os anos de 1779 e 1790, D. Luís de Vasconcelos e Souza ${ }^{8}$, pintura realizada ainda ao final do século XVIII por Leandro Joaquim; e também aquele de José Leandro de Carvalho, que, em 1808, fez o Retrato de D. Maria ${ }^{9}$, com trajes elegantes e, em destaque no primeiro plano, a coroa de Portugal. É possível que este seja o primeiro retrato oficial da corte portuguesa produzido após sua chegada ao Brasil, ainda em 1808 (MEMÓRIA, 2003).

Debret realiza uma série de aquarelas de retratos da família real portuguesa, alguns dos quais foram gravados na obra Viagem pitoresca e histórica ao Brasil. No álbum, ele divide suas pranchas entre o gênero masculino, com os retratos D. João Vle D. Pedro I, e o feminino, com Rainha Carlota, Arquiduquesa D. Leopoldina e Segunda Imperatriz do Brasil, D. Amélia de Leuchtenberg. Fez também uma última série de bustos, homenageando aqueles que colaboraram e protegeram os artistas franceses no conturbado período de implantação do projeto de ensino artístico no Brasil, o que revela ainda uma estreita afinidade política com estes mesmos personagens. Eram eles: Ministro Conde da Barca, Marquês de Marialva, José Bonifácio de Andrada e Silva, José Clemente Pereira e Bispo Capelão-Mor do Rio de Janeiro ${ }^{10}$.

Esta série de bustos e retratos indica as características de cada indivíduo, tanto no que diz respeito à sua descrição física, geralmente feita de maneira realística, quanto na representação política, de acordo com o papel que the cabia na sociedade da corte. Mediante atributos iconográficos, relata as diferenças sociais e hierárquicas, esclarecendo por meio do instrumento visual o período político vivenciado pelo Brasil.

\section{Retrato de D. João VI}

Em seu álbum iconográfico, Debret representa a família real portuguesa primeiramente sob a forma de busto. D. João VI e D. Pedro / (Figura 1) são figurados a meio-corpo, vestidos com as insígnias portuguesas e numerosas
8. Este retrato, feito por Leandro Joaquim, está conservado no Museu Histórico Nacional do Rio de Janeiro.

9. Este retrato de D. Maria I está conservado no Museu Histórico Nacional do Rio de Janeiro.

10. Ver DEBRET, 1972. 


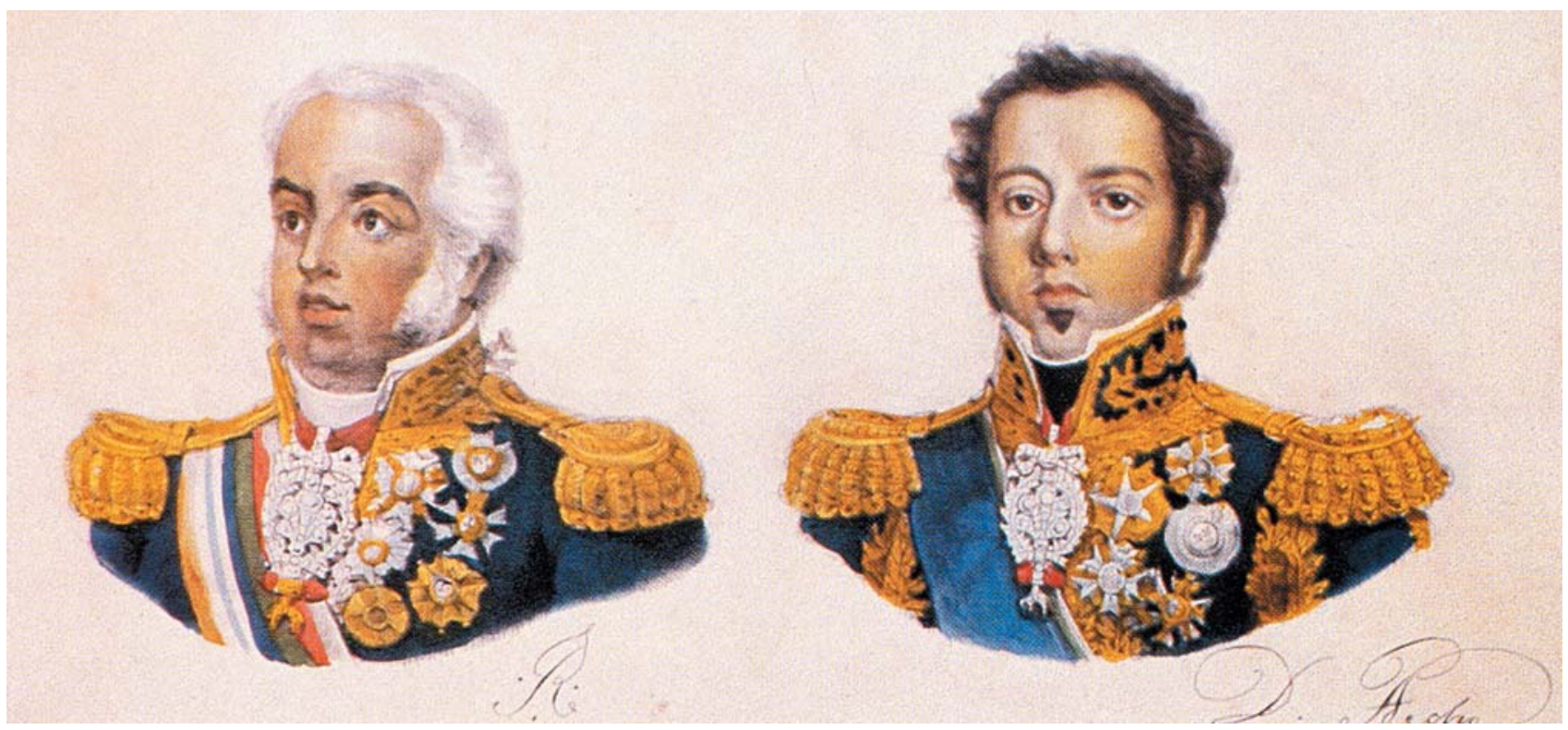

Figura 1 - Jean-Baptiste Debret, Retratos de D. João VI e D. Pedro I. DEBRET, Jean-Baptiste. Viagem pitoresca e histórica ao Brasil. Trad. Sérgio Milliet. Belo Horizonte: Itatiaia; São Paulo: Edusp, 1989. v. III, prancha 10. Reprodução digital de José Rosael. Acervo do Museu Paulista da Universidade de São Paulo, São Paulo.

11. Segundo a tradição bragantina, respeitava-se o mito do retorno de $\mathrm{D}$. Sebastião, desaparecido na África, que então traria a Portugal a coroa de saparecida em combate. Por isso, os reis da dinas tia de Bragança não eram mais coroados, sendo somente aclamados. Deixava-se, assim, a coroa intocada, ao lado do trono. Cf SOUZA, 1999, p. 33. condecorações que thes conferem hierarquia. Em seguida, na mesma prancha, Debret representa-os em dois retratos de corpo inteiro. D. João está vestido com o manto com que foi aclamado rei do Reino Unido de Portugal, Brasil e Algarves em 1818. Cetro e coroa permanecem a seu lado, simbolizando a aclamação e a não-coroação dos reis portugueses, atendendo à tradição da Casa de Bragança" ${ }^{11}$. Ao mesmo tempo, a composição do retrato de D. João VI remete-o à tradição retratística dos reis franceses, como veremos adiante.

Na descrição que acompanha as pranchas de retratos, Debret oferecenos primeiramente as informações referentes à família real Portuguesa, apresentando-nos D. João como o filho de D. Maria I (falecida em 1816 no Rio de Janeiro), regente de Portugal e aclamado soberano do Reino Unido de Portugal, Brasil e Algarves. Cita ainda a perda, aos 55 anos de idade, da coroa do Brasil para o filho D. Pedro em 1822, bem como sua morte em Lisboa em 1825. Debret faz uma breve apresentação política do rei D. João VI, descrevendo-o fisicamente como um homem obeso, de mãos e pés pequenos. A personalidade tímida, a afeição dispensada aos seus camareiros e reposteiros, que "cumulava de empregos lucrativos", são citados por Debret como características particulares ao rei que, segundo o pintor, trouxe ao Brasil e, em sua partida, levou novamente consigo "os abusos de uma velha corte". As palavras de Debret relacionam-se diretamente à sua condição de pintor neoclássico, formado na Paris revolucionária, cuja experiência com o mestre David revelava o desejo dos neoclássicos franceses de afastar os privilégios do Antigo Regime e instaurar um 
governo regido pelas Luzes. A relação se repete quando Debret demonstra sua preferência política centrada na figura de D. Pedro, esperando dele os avanços 12. DEBRET, 1972, p. 151152

à sociedade brasileira, em detrimento dos "abusos da velha corte" de D. João VI. É possível, assim, identificarmos as preferências político ideológicas de Debret no tratamento e construção de suas imagens, reveladas ainda na crítica contida nas descrições das pranchas.

[D. Pedro] de natural pouco generoso, era igualmente econômico na sua maneira de viver. A boa fé fez dele um reformador cuidadoso dos abusos que o haviam revoltado desde a infância na Corte de seu pai ${ }^{12}$.

Debret realizou também um retrato a óleo de D. João VI, hoje presente no Museu Nacional de Belas Artes do Rio de Janeiro (Figura 2). Este retrato apresenta a mesma estrutura e composição da ilustração posteriomente presente

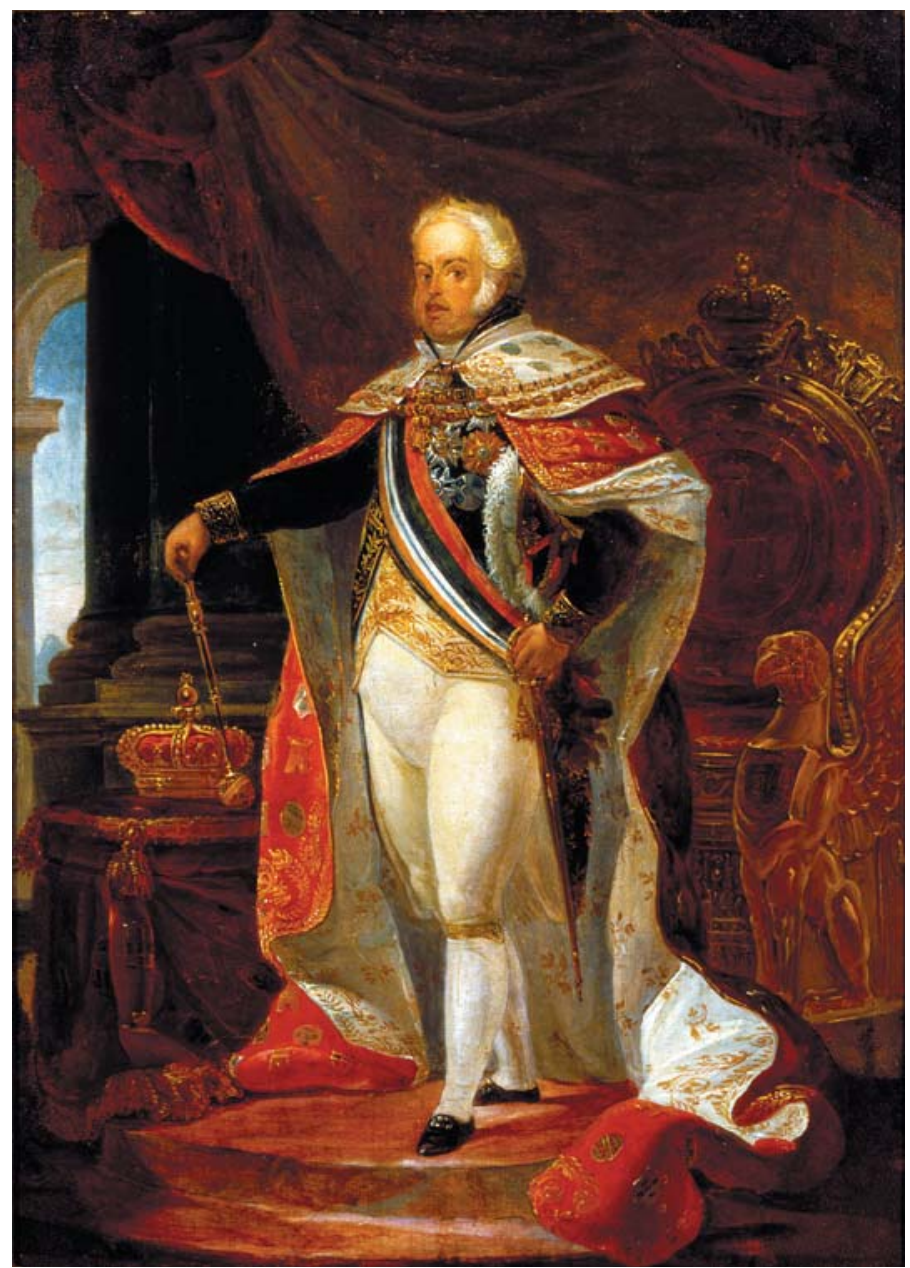

Figura 2 - Jean-Baptiste Debret, Retrato de D. João VI, 1817, óleo s/ tela, 0,60m x 0,42m. Acervo do Museu Nacional de Belas Artes/IPHAN/MINC, Rio de Janeiro. 
13. Há uma cópia desta tela conservada no Museo del Prado, em Madrid, desde 1864 , doada por Isabel II, que a comprou da família do conde de Aranda, embaixador de Carlos III na França. O Conde de Aranda recebera este retrato como presente do próprio Luís XVI, em sua estadia francesa. Há ainda outras cópias nos museus franceses: Musée de Vernon, Musée Bargoin e Musée du Tapis, em Clermond-Ferrand, e também no Château Compiègne. Fontes:Agence Photographique - Réunion des Musées Nationaux : www photo.rmn.fr. ; Joconde Catalogue des Collections des Musées de France: http://www.culture. gouv. fr/documentation/ joconde/fr/pres.htm. 20/04/2006.

\section{LEVEY, 1993}

15. Peter Burke, em sua obra A fabricação do rei: a construção da imagem pública de Luís XIV, analisa as diversas representações do Rei Luís XIV ao longo de seus 72 anos de reinado (1643-1715). Da representação como bebê àquela em cadeira de rodas, ao final da vida, sua imagem sofrera inúmeras revisões e oferecia modelos diversos para as cortes européias, ora representado como Carlos Magno, ora como Augusto ou Constantino, e, ain $\mathrm{da}$, associado às figuras religiosas ou bíblicas, como São Luís e Salomão, entre outros. BURKE, 1994 em Viagem pitoresca e histórica ao Brasil. $\bigcirc$ rei está de corpo inteiro junto ao trono, portando os trajes de realeza. No óleo, há a inclusão do trono e do cenário ao fundo, atrás de D. João VI. Os detalhes do trono podem ser percebidos pelo processo descritivo realizado pelo pintor. $\bigcirc$ encosto da cadeira apresenta como características a coroa na parte superior, estando logo abaixo o símbolo de seu nome "J VI", rodeado de estrelas, e o símbolo da Casa de Bragança: a serpe com o brasão imperial no peito. $\bigcirc$ trono dourado e os trajes majestáticos revelam-nos a imponência da majestade e do próprio reino, agora também americano, que acabava de instaurar-se. O traje imperial foi usado por D. João somente no dia de sua aclamação e Debret pintou-o com todos os detalhes, salientando suas partes bordadas em ouro, evidenciando as insígnias de todas as ordens reluzentes em seu peito, assim como as jóias reais que lhes perpassavam os ombros com seus mais ricos atributos. A presilha de diamantes fechava-se em seu peito, reluzindo ainda o ouro, a prata e as pedras de aço polido, dentro e fora do manto, oferecidos aos olhos de quem quisesse admirá-las no dia de sua aclamação. D. João tem, sob o braço esquerdo, o chapéu real ornado de plumas brancas e brilhantes, segurando em uma das mãos a espada não desembainhada, em ouro e, na outra, o cetro que repousa sobre a mesa almofadada de veludo. Nesse mesmo móvel, permanece intocada a coroa, detalhe que também pode ser conferido na ilustração do álbum iconográfico de Debret. Ao fundo, a arquitetura clássica é representada pela grande coluna dórica, à maneira dos retratos tradicionais de realeza, de onde, ao alto, desenrola-se uma grande cortina que se mantém atrás do trono imperial, num jogo de cores verde e vermelho opacas, recordando as cores portuguesas. D. João VI está iluminado, assim como seus atributos reais - trono, manto, coroa e cetro -, os quais salientam seu caráter de realeza suprema, aclamado em 1818, em uma arquitetura simbólica, ornamentada pelo arquiteto Grandiean de Montigny e pelo próprio Debret.

Na iconografia de D. João VI, podemos notar uma semelhança com a iconografia dos grandes reis do Antigo Regime europeu. Alguns exemplos nos servem de apoio. Luís XVI, monarca de quem Debret fora súdito na França até a Revolução, foi representado no retrato realizado por Antoine Callet, aproximadamente em 1779, com o suntuoso manto azul decorado com a florde-lis, vestido de branco, a perna esquerda à frente, e o cetro na mão direita. Atrás, permanece a cortina, a grande coluna que ocupa todo o lado esquerdo do segundo plano e o trono. Este retrato de Callet, hoje conservado no Castelo de Versailles (Figura 3), na França, foi o modelo utilizado para a produção de diversas cópias a serem enviadas às cortes estrangeiras ${ }^{13}$ e também aos nobres da corte francesa. Podemos ainda remeter o retrato de D. João VI a uma imagem um pouco mais distante, realizada no início do século XVIII, o Retrato de Luís XIV, feito pelo pintor Hyacinthe Rigaud em $1701^{14}$ (Figura 4), que serviu de modelo não só à execução de Callet como também a diversos retratos de corte em outras monarquias na Europa. $\bigcirc$ retrato, que fora oferecido ao rei da Espanha Philippe $V$, acabou permanecendo na França como um forte símbolo da realeza ${ }^{15}$. 


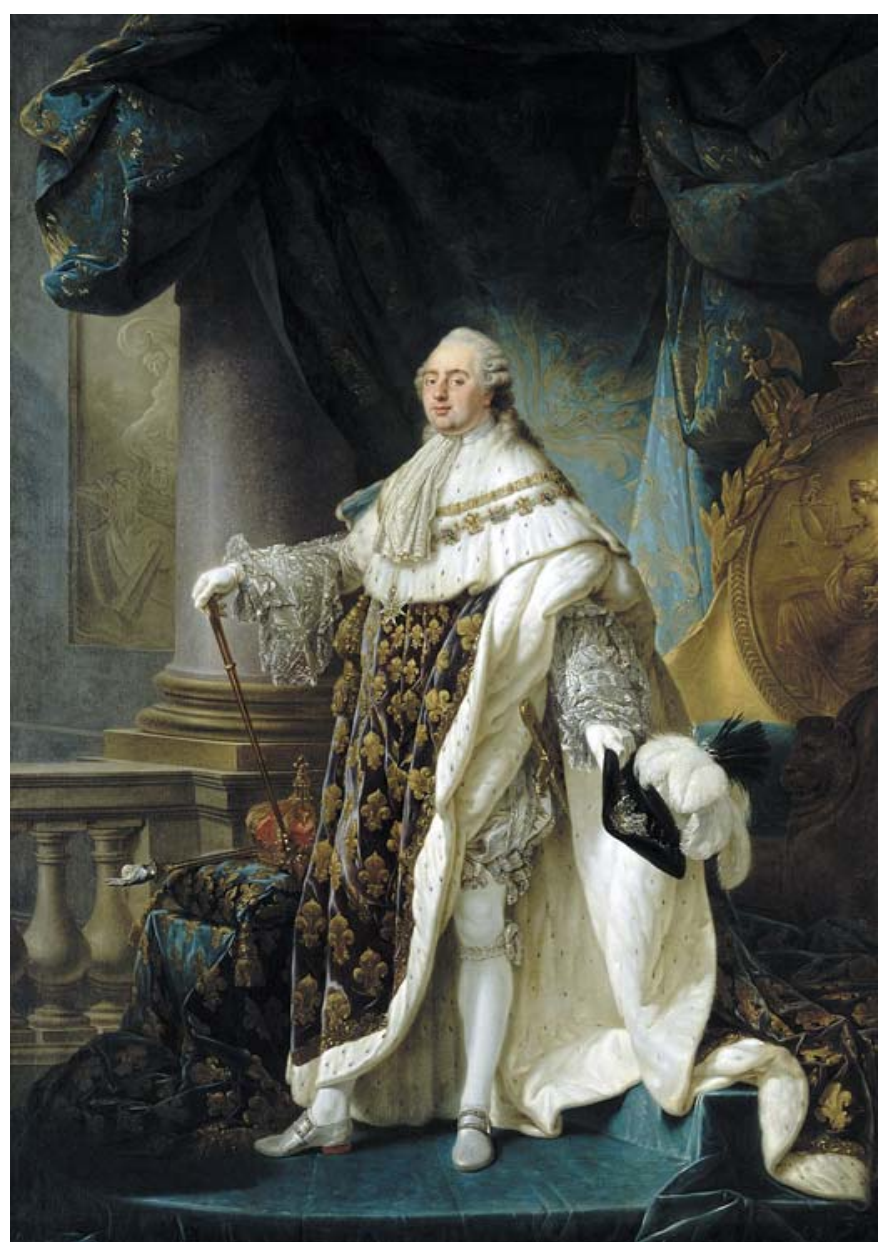

16. É possível pensarmos na hipótese de que este retrato de Debret seja um estudo acabado para um posterior retrato de grandes dimensões, composto no tamanho natural do retratado (não realizado), à maneira de seus modelos europeus.

Figura 3 - Antoine-François Callet, Retrato de Luís XVI, ca. 1779, óleo s/ tela, 2,78m x 1,96m. Chateaux de Versailles et Trianon, Versailles. Photo RMN, (c) Gérard Blot.

A pose do rei Luís XIV, com sua perna direita estendida à frente e sua espontaneidade ao segurar o cetro, sem perder, contudo, a firmeza do toque, remonta-nos finalmente ao Retrato de Carlos I, rei inglês representado como cavaleiro pelo pintor holandês Van Dyck em 1635.

Embora o retrato realizado por Debret seja de pequenas dimensões ${ }^{16}$, diferentemente daqueles antes citados, a comparação é direta no que se refere à composição. A posição dos retratados se repete também em D. João VI. Assim como Luís XIV e Luís XVI, D. João segura seu cetro na mão direita, apoiando-o na mesa em que se encontra também a coroa. Os reis têm, ainda, a espada à mostra em meio ao manto suntuoso. Em Rigaud, o manto de sagração é azul, decorado com flores-de-lis douradas e arminho. Em D. João VI, os bordados são cuidadosamente mostrados em ouro sobre o tecido vermelho, dando-lhe uma iluminação grandiosa que reflete a majestade dos reis, intensamente metaforizada em Luís XIV, o Rei-Sol, iluminado e heróico. Ambos os tronos se encontram no 


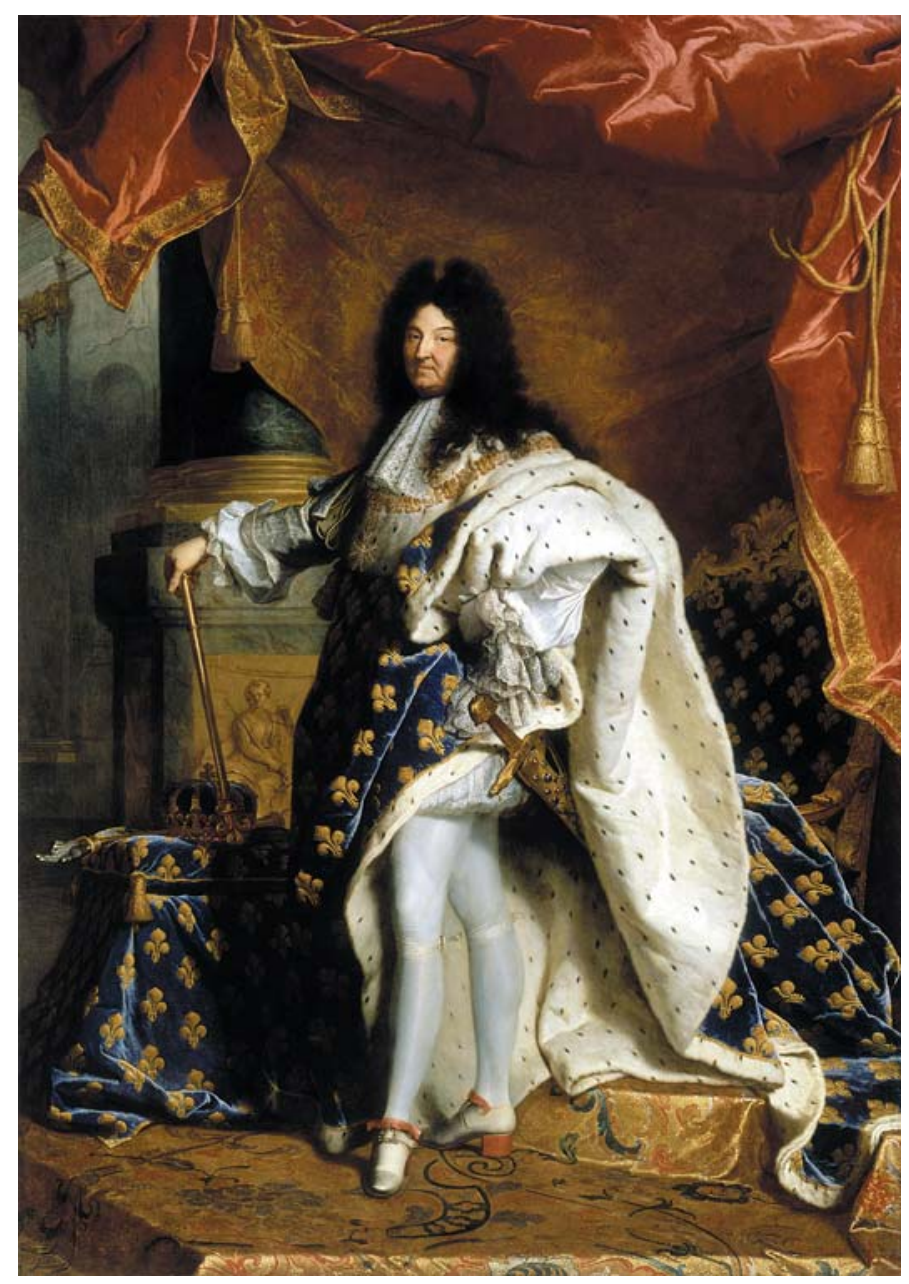

Figura 4 - Hyacinthe Rigaud, Retrato de Luís XIV, 1701, óleo s/ tela, 2,77m x 1,94m. Musée du Louvre, Paris. Photo RMN, ( ) Gérard Blot.

canto direito dos quadros. Em Rigaud, está disfarçado à sombra, encoberto pelo manto que ocupa a cena em quase todo o centro, ao contrário de Debret, que dá ao trono um grande destaque, evidenciando as serpes da Casa de Bragança. Mas o fundo é semelhante, com a grande cortina que compõe o alto da cena e a antiga coluna dórica no canto esquerdo da tela, que se sobressai fortemente, em Rigaud, com o relevo da alegoria da Justiça em sua base.

Para a realização do Retrato de D. João VI, Debret recupera o consolidado modelo de Rigaud que, como dissemos, foi intensamente explorado em outras representações reais do século XVIII em toda a Europa. Assim, na visão de Debret, a imagem de D. João VI aproxima-se àquelas de Luís XIV e Luís XVI. Não há, portanto, inovações, nem políticas nem pictóricas, mas sim o uso de um modelo consolidado e, ao mesmo tempo, ultrapassado de monarquia, identificado por Debret através de seu retrato. Para compor a imagem de D. 
Pedro I, no entanto, o pintor utilizará outros meios para a composição, opostos àqueles empregados na de seu pai, conforme veremos a seguir.

Retrato de D. Pedro I

modelo proposto por Debret para o Retrato de D. João VI não se aplica à representação criada para D. Pedro I. No retrato deste último, ilustrado na obra Viagem pitoresca e histórica ao Brasil, percebemos como a aplicação de novos atributos iconográficos relaciona-se diretamente às mudanças relativas à política brasileira, isto é, a elevação do Brasil a império independente de Portugal em 1822, como notaremos adiante.

Ao contrário de D. João VI, D. Pedro é mostrado com uma vestimenta diferente, portando uma espécie de manto que nos remete ao poncho, traje então utilizado pelos habitantes do sul do país e de São Paulo, bordado em ouro com as insígnias brasileiras, forrado de seda amarela para evitar o calor, além da murça feita com plumas de tucano ${ }^{17}$. Desse modo, para a composição do manto, são recuperados elementos da terra brasileira: as cores verde e amarela, as plumas de uma ave brasileira, além de sua forma aproximada à do poncho, um traje pertencente aos usos e costumes do Brasil, também utilizado pelos cavaleiros brasileiros.

A espada está desembainhada, e um detalhe nos chama a atenção mais prontamente: a presença das botas de cavaleiro. Tanto no retrato presente em seu álbum iconográfico, quanto na monumental tela da Coroação de D. Pedro 1 $^{18}$ (Figura 5), realizada em 1826, Debret representa o imperador com suas botas.

Mário Pedrosa já discorrera longamente sobre a questão das botas, comparando este retrato de Debret àquele feito pelo pintor português Henrique José da Silva, Retrato do imperador em trajes majestáticos ${ }^{19}$ (Figura 6). Este último realizara o retrato de D. Pedro I também de botas, sendo em princípio recusado pelo gravador F. Forster, de Paris, e depois causando grande estranhamento ao gravador Urbain Massard:

[...] o desenho em questão só pode ter sido feito por um homem estranho às artes. É uma produção bem abaixo do medíocre, e eu duvido que algum gravador queira se encarregar de traduzi-la face à ausência total dos primeiros princípios de composição, de traje, de desenho e de efeito.

[...] Eu me encarregarei com prazer, embora haja coisas que firam um pouco a vista; tais que as botas com manto real; mas visto que é uso no Brasil, o uso tudo justifica ${ }^{20}$.

traje, portanto, chamava a atenção dos gravadores franceses, não acostumados a este tipo de representação real, embora Urbain Massard reconheça a importância dos usos e costumes para a composição. Pedrosa destaca a peculiaridade das botas e do manto real no Brasil Império, símbolos inaugurados por D. Pedro I, diretamente contrapostos aos trajes de D. João VI,
17. "O bordado de estilo largo lembra, pela sua forma, grupos de folhas de palmeira e frutos da mesma árvore; grandes estrelas de oito pontas, semeadas no fundo, completam a riqueza desse manto, cuja execução merece justos elogios" (DEBRET, 1972, p. 161).

18. A monumental pintura a óleo da Coroação de D. Pedro I está conservada no Palácio do Itamaraty, em Brasília. O mesmo quadro está presente na ilustração de seu álbum iconográfico, que aqui visualizamos.

19. Vemos aqui a gravura da tela feita por Henrique José da Silva, hoje conservada no Museu Imperial em Petrópolis.

20."[..] le dessin en question ne peut avoir été fait que par un homme étranger aux arts. C'est une production fort audessous du médiocre, et que je doute qu'aucun graveur veuille jamais se charger de la traduire y ayant absence totale des premiers principes de composition, de costume, de Dessin, et d'effet." "Je m'en chargerai avec plaisir, quoiqu'il y ait des choses qui blessent un peu la vue; tels que les bottes avec le manteau royal; mais puisque c'est l'usage au Brésil, l'usage justifie tout." Tradução livre da autora. O primeiro trecho é do gravador $\mathrm{F}$. Forster e o segundo do gravador Urbain Massard. São trechos de cartas encontradas por Mário Pedrosa no Arquivo Histórico do Itamaraty, reproduzidas no artigo Rivalidade luso-francesa na iconografia imperial (PEDROSA, 1955). 


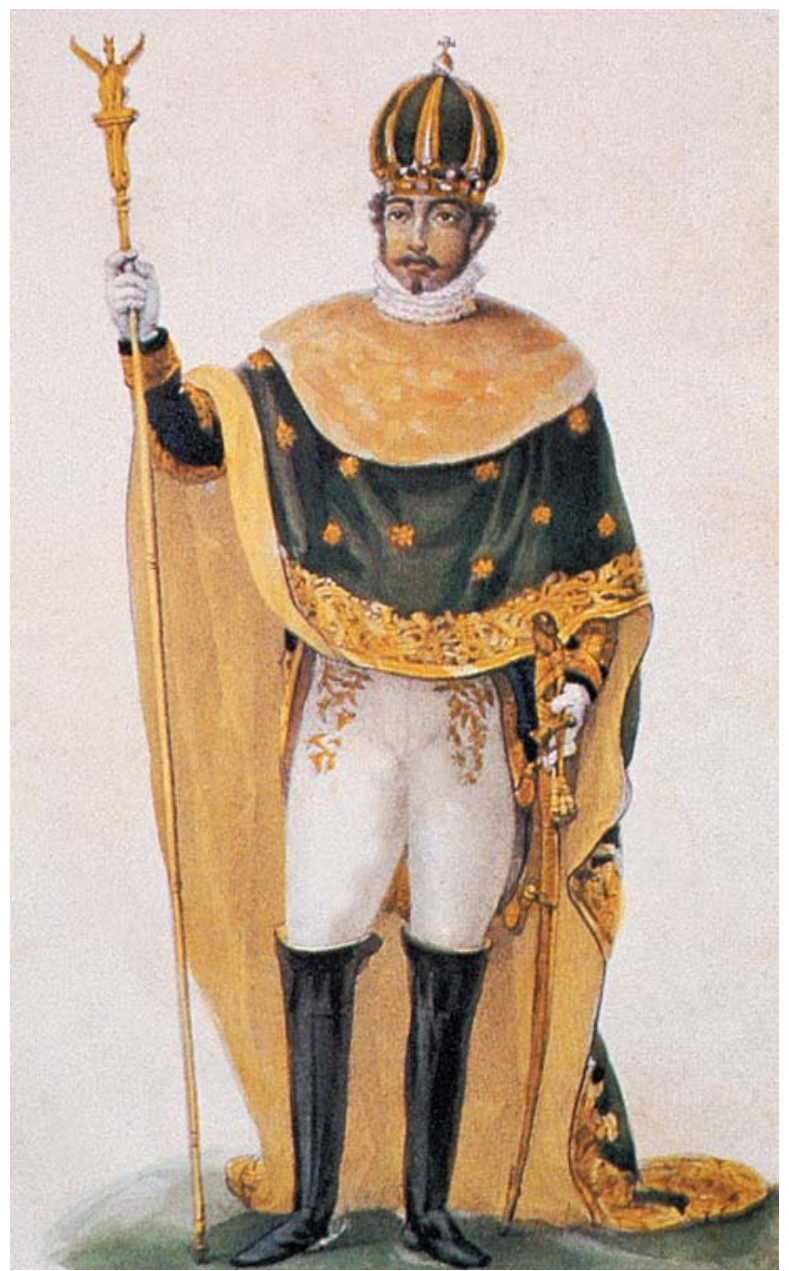

Figura 5 - Jean-Baptiste Debret, Coroação de D. Pedro I, gravura. DEBRET, Jean-Baptiste. Viagem pitoresca e histórica ao Brasil. Trad. Sérgio Milliet. Belo Horizonte: Itatiaia; São Paulo: Edusp, 1989. v. III, prancha 10. Reprodução digital de José Rosael. Acervo do Museu Paulista da Universidade de São Paulo, São Paulo.

pintado por Debret alguns anos antes. Debret, o "pintor de história e extremamente cioso da exatidão dos costumes, etiqueta, cerimônia", pinta D. João VI de acordo com a tradição em que estava inserido, isto é, representa-o com suas calças presas aos joelhos, manto real, cetro, e coroa depositada ao lado. No que se refere a D. Pedro, suas botas revelam a personalidade ativa do jovem imperador, simbolizando a "força" com que conseguira tornar o Brasil independente. Era o imperador americano, e caudilho, não se separando de suas botas nem mesmo nas ocasiões solenes da realeza. Foi também a marca registrada de sua coroação e algo que era aceito pelo Rio de Janeiro e pelos estrangeiros que aqui viviam, como Debret, por exemplo. Era, portanto, o símbolo do Imperador ${ }^{21}$. Ao mesmo tempo, o uso de botas remetia D. Pedro ao militarismo. A fonte iconográfica mais direta é a representação do próprio Napoleão em suas campanhas ainda 


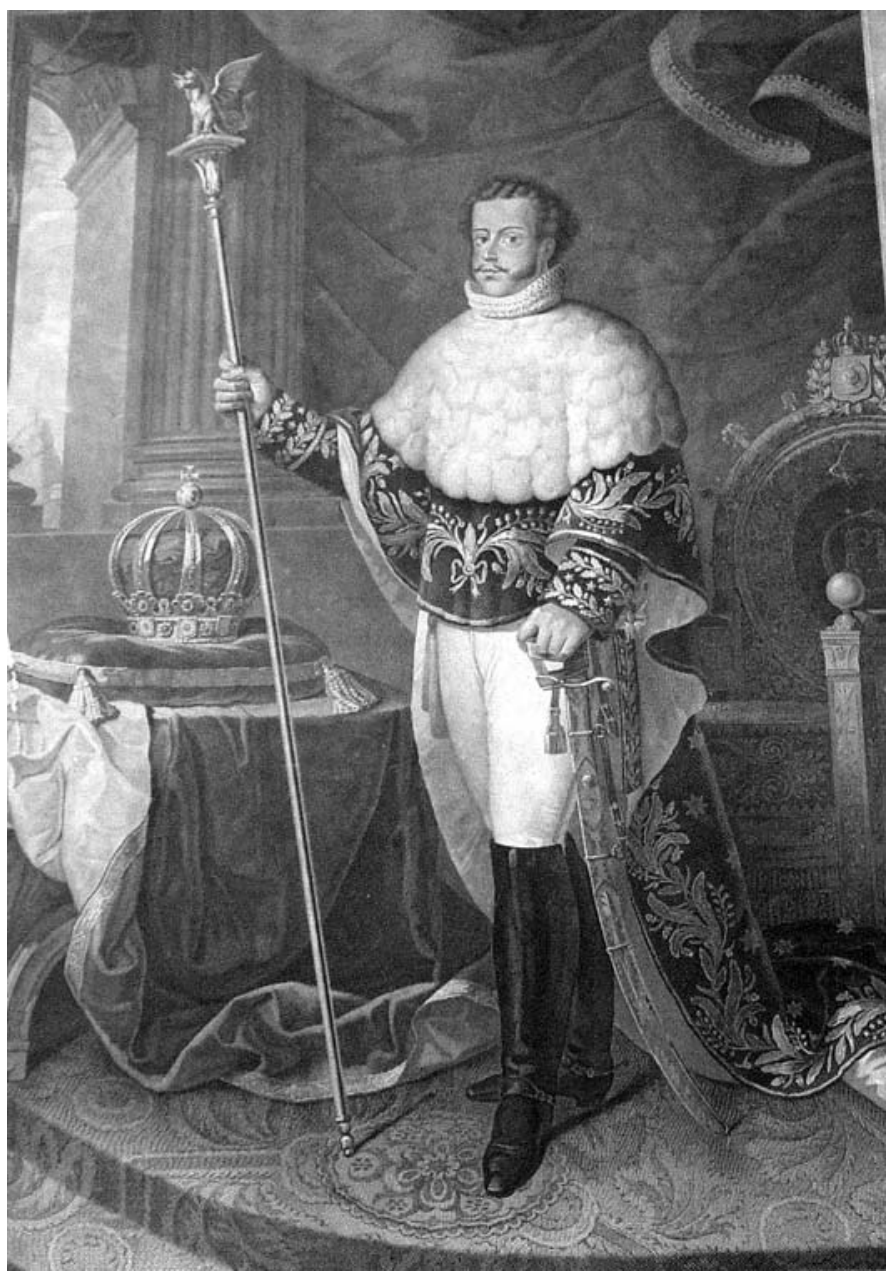

22. O primeiro óleo feito por José Gil de Castro pode ser aquele exposto no Palácio Nacional de Caracas, na Venezuela.Há também outro, uma cópia do primeiro, feito pelo próprio artista, na Assemblea Nacional de Peru.A representação de Gil encontrou grande sucesso no período, e foram realizadas muitas cópias de sua tela assim como um grande número de gravuras. Há ainda outras reproduções no Museo Nacional de Arqueologia, Antropologia e Historia de Peru, e gravuras espalhadas pela América Latina, como no Museo Histórico Nacional de Buenos Ayres e em outros museus na Venezuela (Caracas) e na Bolívia. Ver ALVAREZ, 2004.

Figura 6 - Henrique José da Silva, Retrato do Imperador em trajes majestáticos, c. 1822, gravura sobre metal feita por Urbain Massard, 0,64m x 0,44m. Reprodução de Elaine Cristina Dias. Acervo do Museu Imperial/IPHAN/MINC, Petrópolis, Rio de Janeiro.

como general Bonaparte, pintado também por Debret em diversas ocasiões antes da migração para o Brasil.

No ambiente latino-americano, é importante destacarmos, inclusive, que, em meio à iconografia dos grandes líderes, as botas surgiam em razão do caráter vigoroso e dinâmico dessas lideranças. Assim como Bonaparte, também esses eram militares. Podemos ainda remeter o retrato de Pedro I àquele de Simón Bolívar, pintura a óleo criada em 1825 pelo artista peruano José Gil de Castro $^{22}$, em que ele é representado no momento de grande prestígio e poder, quando fundava a Grande Colômbia, Peru e Bolívia. Nesta pintura, Gil representao como um grande militar - vestido à maneira de Napoleão, com a mão direita levemente inserida no traje -, com eminentes botas negras, acompanhado de sua espada desembainhada, e que, assim como D. Pedro I, passa a ser figurado 
como um imponente caudilho, libertador da América. Assim, Gil passou para a tela o glorioso momento da transição do colonialismo para a independência, criando a monumental iconografia que se cristalizaria como a imagem do herói Bolívar.

Voltando a D. Pedro I, além das botas, Henrique José da Silva retratouo com a coroa depositada ao lado, do mesmo modo como Debret compôs D. João VI, reforçando o símbolo que remete à tradição da Casa de Bragança. Em Debret, D. Pedro está com a coroa à cabeça, evidenciando, por um lado, a ruptura da tradição, isto é, a inovação, e, por outro, a conquista do império brasileiro pelas mãos de um português, que agora, de certa maneira, recupera a coroa de D. Sebastião em outros domínios. Ruptura da tradição de um lado e recusa desta mesma ruptura de outro, reforçando a tradição. Debret e Silva divergem iconograficamente quanto à atitude de D. Pedro em relação a Portugal.

Ora, Henrique José da Silva, chefe do partido luso em briga contra os artistas franceses, apesar de pintor da Câmara de Sua Majestade Imperial, fez o retrato dele de acordo com a tradição sebastianista, isto é, colocou a coroa não sobre a cabeça do Imperador mas na mesinha ao lado esquerdo, tal como na iconografia de D. João VI. Em compensação, retratou-o, apesar dos trajes majestáticos, de botas. Que era algo de insólito, bem o diz o escândalo que causou aos gravadores de Paris. Debret, entretanto, o retratou também de botas, manto real, coroa e cetro, isło é, au grand complet, e não se escandalizou. Não fez nenhum comentário a propósito, apesar de considerar, como fazendo parte indispensável ao gênero de pintura em que era especializado, o respeito da pragmática e da exatidão dos cerimoniais ${ }^{23}$.

Debret, como pintor de história interessado não somente na exatidão do cerimonial, reforça os atributos de D. Pedro, utilizando-os como instrumentos de persuasão a partir de uma composição calculada, de modo a construir a cena, associando-a ao elemento verossímil. Reforça, portanto, as características de D. Pedro associadas à história da ruptura entre Brasil e Portugal, isto é, através de elementos como o manto, as botas e a coroa à cabeça. Além disso, Debret encontra em D. Pedro a grande promessa de inovação e progresso que os partidos liberais viam como saída para o Brasil. Silva, ao contrário, nega-se a colocar D. Pedro como o homem que se tornou imperador de um país independente de Portugal e que leva sua coroa, estando o pintor ainda intimamente ligado ao reino português. Podia, ainda, achar-se convicto da volta de uma soberania portuguesa; ou simplesmente acreditar na figura de D. Pedro como aquele que, ao invés de romper, deu continuidade ao reino português, ainda que agora o Brasil se encontrasse numa posição política autônoma.

Ao mesmo tempo, podemos aproximar o pintor Debret do pintor Rigaud, não através da iconografia desses retratos, mas sim pela maneira como os artistas se portavam na composição da imagem dos grandes líderes, trabalhando igualmente no sentido da criação de uma imagem que convencesse - as técnicas de persuasão - e que demonstrasse uma rica afinidade com o momento político representado. Debret reforça, por um lado, os atributos 
tradicionais de D. João VI, necessários à sua época, como o fortalecimento de seu poder na continuidade do reino de Portugal no Brasil; e, por outro, inova na imagem de D. Pedro, com atributos obrigatórios ao novo status político e fortemente ligados aos elementos nacionais, como podemos notar nos trajes e em suas insígnias reais.

Um ponto curioso que nos remete novamente às praticas de representação utilizadas por Luís XIV é o uso atribuído ao retrato. Comumente ele era utilizado como personificação do monarca, ocupando o seu lugar em momentos de sua ausência, sendo igualmente respeitado pelos súditos como se ali estivesse presente. $\bigcirc$ retrato feito por Rigaud teria substituído o monarca em várias ocasiões, fazendo as vezes de Luís XIV até mesmo na sala do trono de Versailles, recebendo todas as homenagens e sinais de respeito em lugar do soberano francês. Da mesma maneira, o retrato seguia em seu lugar nas grandes festividades provinciais, carregado em procissões e diretamente associado à imagem de um santo. $\bigcirc$ Rei era, portanto, a personificação de Deus e do Estado. No Brasil, tal prática também foi utilizada no período colonial, mas principalmente nas festas da Independência que ocorriam pelas províncias do território. A ligação com o uso da imagem no reinado de Luís XIV é imediata, ainda que a figura de D. Pedro se distanciasse sobremaneira daquela do rei absolutista. Ressalte-se ainda que, além da criação iconográfica inovadora de Debret, outros artistas também realizaram retratos de D. Pedro I a serem distribuídos pelas províncias, como o próprio Henrique José da Silva e Simplício Rodrigues de Sá, sendo o imperador, em alguns deles, caracterizado a meio-corpo e vestido com as insígnias militares.

É necessário avaliarmos, nesse sentido, a importância do retrato oficial nesse contexto histórico específico. Em seus escritos, Carvalho Souza já destacou o uso do retrato do imperador como a sua própria personificação, mostrado em todas as províncias para a adoração de seus súditos, como se ele próprio estivesse ali presente, promovendo a Aclamação em todas as partes da terra independente. Se D. Pedro não podia comparecer, lá estava o retrato, substituindoo à altura:

O retrato preenchia a ausência do soberano, representando-o - ou seja, tornando-o também presente - sem que ele precisasse deslocar-se da capital, exibindo suas qualidades, atributos, e remetia para seu sentido sobrenatural, inserindo-o numa lógica na qual se destacavam os santos, o andor, o pálio ${ }^{24}$.

Nas províncias, as festas políticas aconteciam em torno do retrato, que era colocado ao pé de um trono, e ali as pessoas seguiam para uma espécie de cumprimento semelhante ao beija-mão, recebendo ele cortejos e homenagens. Por onde passava, era sempre acompanhado de salvas de artilharia e de marchas oficiais. $\bigcirc$ retrato entrava nos recintos, geralmente em um pálio muito bem decorado, e era recebido com orquestras e fogos de artifício, como se o imperador ali estivesse para "abençoar" a nova nação. No período de aclamação da 
25. SCHWARCZ, 1999, p. 16.
Independência, o retrato político no Brasil ganhou, portanto, uma grande significação, não só personificando o imperador na presença de seus súditos como também adquirindo um caráter sacro, ocupando o lugar dos santos nos andores de procissões, com um claro objetivo políitico. Usava-se, portanto, de um artifício religioso para exaltar a figura política, a exemplo do que acontecia com os reis absolutistas e, agora, com a exaltação da figura de D. Pedro I. Festas assim, que também aconteceram no período colonial e na aclamação de D. João Vl ao reinado, ganhavam aqui grande notoriedade e ampla divulgação, em razão da mudança de status político. Lília Schwarcz também considera esta questão ao analisar a representação da realeza e sua imediata associação ao caráter religioso da sociedade brasileira:

Com efeito, no Brasil religião e realeza estão ligadas de forma muito peculiar. Aqui não se atribuem ao rei poderes mágicos ou transcendentais [...], porém de toda maneira o ritual local aprimora o "fraco" cerimonial dos Bragança. No Brasil, os imperadores passam a ser ungidos e sagrados numa tentativa de dar sacralidade a uma tradição cuja inspiração era antiga mas a realização datada. Nesse movimento, ao mesmo tempo em que os monarcas ganham santidade, os santos, quando muito adorados, ganham realeza no Brasil. [...] De qualquer modo, mantos imperiais convivem com mantos divinos, e o imaginário da realeza acaba permeando fortemente o catolicismo brasileiro $[\ldots]^{25}$.

Associava-se, deste modo, o caráter religioso da corte dos Bragança - que era efetivamente forte já no reinado de D. João VI e que não fora abandonado nesta construção da representação do imperador - à nova imagem de D. Pedro, a ser explorada no império independente que se formava. Era um elemento amplamente utilizado como instrumento essencial à composição da nova figura do soberano e, sobretudo, sua divulgação nas mais distantes províncias. Em tais ocasiões, havia, portanto, uma evidente mistura entre o caráter político, artístico e religioso em uma verdadeira proliferação do retrato do imperador, homenageado e adorado nas províncias.

Também nesse mesmo sentido, há a valorização do discurso religioso por outra obra de Debret relacionada a D. Pedro I. Não se trata mais de um retrato, mas sim da representação de D. Pedro no quadro de sua coroação. D. Pedro, vestido com seu manto e suas botas de cavalaria, está coroado e sentado ao trono, sagrado imperador na catedral do Rio de Janeiro. Não só a arquitetura barroca sobressai-se na composição, mas igualmente a posição de D. Pedro, que, no trono, recebe as homenagens do presidente do Senado da Câmara do Rio de Janeiro Lúcio Soares Teixeira de Gouveia. Este último, ajoelhado, presta as devidas homenagens ao novo imperador e confere a leitura do juramento. Além do cenário religioso imposto pela arquitetura barroca, a cena tem uma forte conotação religiosa. D. Pedro é respeitado e devotado como aquele que livrou o Brasil dos domínios de Portugal. A metáfora religiosa aparece, portanto, como um instrumento de persuasão e legitimação do poder do soberano. 
Ressalte-se, portanto, que, ainda que seja criada a imagem de um novo imperador, há o uso efetivo de determinados meios tradicionais para exaltar sua importância política, utilizando-se de meios acessíveis e persuasivos ao povo, como no caso da utilização dos retratos nas festas e também de sua conotação fortemente religiosa.

Conclusão

Debret representou D. Pedro como um homem forte e de grande temperamento. Seria, para o pintor, o políitico reformador dos abusos da Corte de D. João VI. Faz um contraponto entre as duas figuras, identificando, tanto na ilustração quanto no texto descritivo, as transformações ocorridas na esfera do Estado daquele período. No entanto, não esconde sua predileção pela política instalada pelos partidos brasileiros ao colocarem D. Pedro no trono, distinguindo claramente as duas figuras portuguesas em suas pranchas. Desta maneira, ao colocar lado a lado em seu álbum iconográfico as ilustrações do rei e do imperador, Debret realiza duplamente a descrição física - a obesidade de um e a vivacidade do outro - e também a contraposição política que deixa transparecer pelos atributos que caracterizam um e outro: o manto feito com plumas de tucano, caracterizando o elemento nacional, a coroa à cabeça, simbolizando a inauguração de um novo período político, juntamente à espada desembainhada, ao cetro e às botas de cavalaria, que associam D. Pedro ao libertador e cavaleiro que, de perto, percorre suas terras.

Além disso, é importante considerar, neste contexto, o uso do retrato oficial. Pela mão de diversos artistas, a imagem de D. Pedro também adquiria o caráter sagrado em sua representação, prática já utilizada no Brasil colônia, mas aqui amplamente difundida. D. Pedro era colocado - através de sua real e divina presença por meio do retrato que the confere a personificação - como um santo que percorre as províncias e recebe as homenagens de seus fiéis súditos em cima de uma espécie de andor e altar, pronto a ser adorado nas festas políticas que se espalhavam pelo Brasil.

Na produção desses dois retratos, Debret identifica, assim, as mudanças políticas e de representação instauradas, presenciadas e documentadas iconograficamente por ele durante os anos em que aqui permaneceu, a partir de seu papel de pintor oficial na corte de D. João VI e, principalmente, na de D. Pedro l, enfatizadas tanto pelas imagens quanto pela pequena descrição que acompanha as ilustrações de sua Viagem pitoresca e histórica ao Brasil. 


\section{REFERÊNCIAS}

ALVAREZ, J.A. La desmonumentalización de Simon Bolívar en El General en su Laberinto. In: La Desmonumentalizión en la novela bistórica de fines del siglo veinte. Austin,Tx.:The University of Texas at Austin, 2004.

BOIME,A. Art in age of revolution, 1750-1800. Chicago:The University of Chicago Press, 1987.

BURKE, P. A fabricação do Rei: A construção da imagem pública de Luís XIV. Rio de Janeiro:Jorge Zahar, 1994.

DEBRET, J.-B. Viagem pitoresca e bistórica ao Brasil. São Paulo: Martins, 1940.

Viagem pitoresca e bistórica ao Brasil. Tomo II, v. III. São Paulo: Martins; Edusp, 1972.

DELÉCLUZE, E. J. Louis David: son école et son temps. Paris: Macula, 1983.

DIAS, E. Debret: a pintura de história e as ilustrações de corte da Viagem pitoresca e histórica ao Brasil. 2001. Dissertação (Mestrado em História)-Instituto de Filosofia e Ciências Humanas, Universidade Estadual de Campinas, 2001.

. Félix-Émile Taunay: cidade e natureza no Brasil. 2005. Tese (Doutorado em História)Instituto de Filosofia e Ciências Humanas, Universidade Estadual de Campinas, 2005.

. Uma carta de Jean-Baptiste Debret ao "Camarade De La Fontaine" na Bibliothèque de l'INHA (França): novos relatos para a história da Missão Artística Francesa no Brasil. Revista de História da Arte e Arqueologia da Unicamp, Campinas, n. 5, 2006 (no prelo).

LEVEY, M. L'art du XVIII siècle. Paris: Flammarion, 1993.

LEVY, H. Retratos coloniais. Revista do Serviço do Patrimônio Histórico e Artístico Nacional, n. 9 , p. $251,1945$.

MEMÓRIA compartilhada: retratos na coleção do Museu Histórico Nacional. Anais do Museu Histórico Nacional, Rio de Janeiro, volume especial, tomo 35, 2003.

MIGLIACCIO, L. Século XIX. In: FUNDAÇÃO BIENAL. Mostra do Redescobrimento Brasil +500: século XIX: catálogo. São Paulo, 2000.

MNBA - Museu Nacional de Belas Artes. São Paulo: Banco Safra, 1985.

PEDROSA, M. Rivalidade luso-francesa na iconografia imperial. Jornal do Brasil, Rio de Janeiro, 15 dez. 1957.

. Da Missão Francesa: seus obstáculos políticos. In: Obras completas de Mário Pedrosa. v. X. Org. Otília Beatriz Fiori Arantes. São Paulo: Edusp, 1995. 
SCHWARCZ, L. M. As barbas do Imperador: D. Pedro II, um monarca nos trópicos. São Paulo: Companhia das Letras, 1999.

SOUZA, I. L. C. Pátria coroada: o Brasil como corpo político autônomo 1780-1831. São Paulo: Fundação Editora da Unesp, 1999.

Artigo apresentado em 12/2005. Aprovado em 04/2006. 